\title{
COR VERSUS GÊNERO:ANÁLISE DISCURSIVA DO DISCURSO DE BOLSONARO NO MARANHÃO E COMENTÁRIOS DE INTERNAUTAS
}

\author{
MARIA DO CARMO GOMES PEREIRA CAVALCANTI ${ }^{1}$ \\ NADIA PEREIRA GONÇALVES DE AZEVEDO \\ Universidade Católica de Pernambuco - UNICAP \\ Rua do Príncipe, 526 - Boa Vista, Recife - PE - 50050-900 \\ Email:carmingpc@yahoo.com.br \\ Email:nadiaazevedo@gmail.com
}

\begin{abstract}
Resumo: Este trabalho analisa a reportagem do Jornal Nacional exibida em 29/10/2020, acerca do discurso do presidente sobre a cor rosa do refrigerante Jesus no Maranhão, e dois comentários de internautas no site da Folha de Pernambuco, no mesmo dia. Assim, à luz do dispositivo teórico e analítico da Análise do Discurso de linha francesa baseado nos estudos de Pêcheux na Europa, e de Orlandi e demais estudiosos no Brasil (AD), este artigo mobiliza as noções de sujeito, memória discursiva, formações imaginárias e discursivas, efeito metafórico, que funcionam como unidades de sentido em relação à situação.
\end{abstract}

Palavras-chave: Discurso do presidente; Memória discursiva; Formação discursiva; Efeitos metafóricos

\begin{abstract}
This paper analyzes the Jornal Nacional report shown on 10/29/2020, about the president's discourse about the pink color of Jesus soda in Maranhão, and two comments from internet users on the Folha de Pernambuco website on 10/29/2020. Thus, from the theoretical and analytical device of the Discourse Analysis of the French line based on the studies of Pêcheux in Europe, and of Orlandi and other academics in Brazil, this paper mobilizes the notions of subject, discursive memory, imaginary and discursive formations, metaphorical effects that function as units of meaning in relation to the situation.
\end{abstract}

Keywords: Discourse by the president; Discursive memory; Discursive formation; Metaphorical effects.

\section{INTRODUÇÃO}

O Jornal Nacional, programa semanal criado em 1 de Setembro de 1969, exibido à noite, pela TV Globo, apresentou, no dia 29 de Outubro de 2020, uma reportagem intitulada: "Bolsonaro" faz piada com refrigerante cor-de-rosa do Maranhão e recebe

\footnotetext{
${ }^{1}$ Doutora em Ciências da Linguagem na Universidade Católica de Pernambuco - UNICAP.

2 Professora/pesquisadora do Programa de Pós-graduação em Ciências da Linguagem na Universidade Católica de Pernambuco - UNICAP. Doutora em Letras e Linguística (UFPB - 2007)
} 
críticas. Na matéria, disponível no site da TV Globo em: https://globoplay.globo. com/v/6980200/, consta a informação que o presidente Jair Messias Bolsonaro enuncia dizeres de cunho homofóbico a partir da cor rosa de um tradicional refrigerante do Maranhão. A "piada" do presidente causou repúdio ao governador do Estado Flávio Dino (PCdoB), que ameaçou processá-lo, como também a deputados como Rubens Pereira Júnior e Márcio Jerry (PCdoB), Bira do Pindoré (PSB) deputado Ivan Valente (PSOL-SP), senador Humberto Costa (PT-PE) e parlamentares do Maranhão e de outros Estados. No site da revista Fórum, intitulado: "Guaraná Jesus, apesar do nome, foi criado por um ateu; conheça a história", traz a reportagem que consta que foram necessárias muitas tentativas até chegar ao sabor agradável. O seu "inventor" chamavase Jesus Norberto Gomes, assumidamente ateu. Iniciou como comerciante aos 20 anos, com uma farmácia. Na época, era comum fazer refrigerantes em farmácia. A bebida mantém sua fórmula original e é distribuída, além do Maranhão, em Tocantins, Piauí, Paraná, São Paulo, Minas Gerais e Brasília.

Em 29/10/2020, o site do jornal Diário de Pernambuco apresenta uma reportagem intitulada: "virei boiola, igual maranhense", diz Bolsonaro após beber refrigerante rosa, típico do Maranhão. Bolsonaro foi acusado de homofobia nas redes sociais por zombar de uma bebida típica da região. Na mesma data, o site jornal de Brasília apresentou matéria intitulada: Bolsonaro faz piada preconceituosa no Maranhão: "virei boiola igual maranhense". Quando estava saindo da Capital São Luís, rumo à cidade de Imperatriz, apoiadores (quase todos sem máscara, assim como Bolsonaro) ofereceram ao presidente um copo do guaraná típico do Maranhão. Bolsonaro aparentou se divertir com a cor da bebida, brincando com as pessoas que se aglomeravam ao seu redor. O momento foi registrado em vídeo pelos apoiadores e publicado nas redes sociais. O presidente foi ao Maranhão entregar obras do Governo Federal e inaugurar um trecho da rodovia BR-135.

Nesse mesmo dia, o site da Folha de Pernambuco aparece a reportagem intitulada: "virei boiola, igual maranhense" diz Bolsonaro no Maranhão após beber refrigerante Jesus, rosa. A reportagem também aborda o mal-estar causado pela "piada" do presidente que em sua primeira visita oficial ao Estado. A equipe ministerial que acompanhava o presidente fazia uma transmissão ao vivo em suas redes sociais. Este mesmo site mostra publicações de internautas, produzindo novos sentidos a partir do enunciado do presidente.

A "piada" de Bolsonaro disseminou repúdio em diversos parlamentares e na sociedade civil. As reportagens mostram indignação e críticas da imprensa nacional sobre o lugar social ocupado pelo presidente e o decoro que lhe cabe como chefe do poder executivo do país.

No mesmo dia, houve publicações sobre o fato em muitos sites, como por exemplo, no site do Jornal de Brasília, intitulado: Bolsonaro pede desculpas por fala preconceituosa após tomar guaraná no Maranhão. Em live nas redes sociais, pediu desculpas ao governador do Maranhão e afirmou que não pretendia ofender ninguém. Em site do jornal Jovem Pan, houve reportagem com título: "ameaçado de processo por Dino, Bolsonaro pede desculpas por brincadeira no Maranhão.” Após repercussão negativa de seu discurso, o presidente afirmou que foi tratado com muito carinho no Maranhão e fez apenas uma brincadeira, mas repercutiu como maldade para muitos. 
Este artigo não pretende analisar o pedido de desculpas do presidente, mas, sim, os efeitos de sentido produzidos por sua "brincadeira", o discurso sobre a cor do guaraná no Maranhão.

Diante do enunciado do presidente em sua visita ao Maranhão, efeitos de sentido circularam nas redes sociais, fazendo emergir comentários à "piada" do presidente em relação à cor rosa do tradicional refrigerante do Maranhão. Este artigo pretende responder às seguintes questões de pesquisa: (i) Que efeitos metafóricos são produzidos pelo discurso do presidente Bolsonaro? Como as formações discursivas e imaginárias se apresentam nos comentários dos internautas? Como a memória discursiva é acionada nesses comentários?

Para responder a tais questões, este trabalho tem como aporte teórico e analítico a Análise do Discurso de linha francesa, delineada na França por Michel Pêcheux e desenvolvida no Brasil por Orlandi e demais estudiosos.

Este artigo está distribuído de forma a apresentar ao leitor as considerações iniciais, justificativa, objetivo e procedimento metodológico. A segunda parte do trabalho pretende brevemente, tecer algumas considerações teóricas acerca da teoria e procedimentos analíticos em que se apoia o trabalho, a Análise do Discurso de linha francesa, fundada por Pêcheux na Europa e desenvolvida, no Brasil por Orlandi e outros estudiosos. Em seguida, pretende-se trazer a análise do corpus discursivo constituído pela "piada" do presidente e dois comentários de internautas no site da Folha de Pernambuco, no dia 29/10/2020, focando nas noções de posições-sujeito e dos efeitos de sentido produzidos a partir desses lugares de presidente e internautas, como lugares inscritos na historicidade pela exterioridade constitutiva. Por último, haverá o efeito de fechamento do trabalho com as considerações finais.

\section{POSIÇÕES-SUJEITO; DISCURSO; FORMAÇÃO DISCURSIVA; FORMAÇÕES IMAGINÁRIAS, MEMÓRIA DISCURSIVA, EFEITOS METAFÓRICOS}

Conforme Pêcheux (1969, 1975, 1999, 2008) o discurso é o efeito de sentidos entre locutores. O discurso também é estrutura e acontecimento. É estrutura, porque trabalha-se com a língua, o enunciado. É acontecimento, no ponto de encontro entre uma atualidade e uma memória. Para Orlandi (2013), etimologicamente, discurso traz em si a ideia de percurso, movimento. O discurso é a movência da palavra, é um objeto sócio histórico em que o linguístico intervém como pressuposto relacionando à sua exterioridade. A exterioridade constitutiva é o interdiscurso.

Conforme Pêcheux (1969), os sujeitos ocupam lugares numa formação social. Esses lugares são representações no discurso. Para Orlandi (1998, 2013), o sujeito corresponde a um lugar de significação historicamente constituído, uma "posição". O sujeito na $\mathrm{AD}$ não é empírico, nem ocupa lugares objetivos na estrutura social. Conforme Pêcheux (1969); Pêcheux e Fuchs (1975); Pêcheux (2008, 2009) e Orlandi (2012a, 2012b, 2012c, 2007, 2013) o indivíduo se constitui em sujeito pela interpelação ideológica e pelo discurso do outro e do "Outro" (inconsciente/interdiscurso). A interpelação do sujeito refere-se a (des) identificação 
com a formação discursiva que o domina. A noção de Formação Discursiva (FD), imbricada com a noção de formação ideológica foi decorrente da leitura que Pêcheux fez de Althusser em obra intitulada "Aparelhos Ideológicos do Estado", o que explica seu laço com o marxismo, como afirma Silva (2019). A noção de formação discursiva foi criada por Foucault e reelaborada por Pêcheux, que incorporou em seus estudos a ideologia materializada no discurso. Pêcheux expõe o que compreende por formação discursiva:

chamaremos, então, formação discursiva aquilo que, em uma formação ideológica dada, isto é, a partir de uma posição dada em uma conjuntura dada, determinada pelo estado da luta de classes, determina o que pode e deve ser dito ( articulado sob a forma de uma alocução, de um sermão, de um panfleto, de uma exposição, de um programa, etc. (PÊCHEUX, 2009, p.147).

Indursky (2011, p.82-84), numa leitura de Pêcheux (2009, p. 199-202), retoma as modalidades de tomada de posição do sujeito em uma formação discursiva e afirma que a forma-sujeito pode fragmentar-se em diferentes posições. Na identificação, o sujeito assujeita-se a uma FD sob a forma de "livremente consentido". Só há espaço para os mesmos sentidos e não para a diferença, contradição. É o discurso do "bom sujeito". Na contraidentificação o sujeito toma uma posição, que se contrapõe à forma sujeito e os saberes que ela organiza no interior da FD. Abre-se espaço para dúvida, distanciamento, contestação. É o discurso do "mau sujeito". Na desidentificação, ocorre uma ruptura com os saberes de uma FD e desidentificação com sua forma-sujeito. $\mathrm{O}$ sujeito passa a inscrever-se em outra FD, há um deslocamento.

A diferença entre formações discursivas e sua fluidez possibilita a movência dos sentidos. Segundo Pêcheux (1969) e Orlandi (2013), numa sociedade hierarquizada, um dizer tem mais valor que outro, dependendo do lugar social do sujeito que enuncia.

Segundo Pêcheux (1969, p.76-77),

O orador é capaz de se colocar do ouvinte a partir do próprio lugar, sua habilidade de imaginar, de preceder o ouvinte é, às vezes, decisiva se ele sabe prever, em tempo hábil, onde este ouvinte o espera. Esta antecipação do que o outro vai pensar parece constitutiva de qualquer discurso [...]. (PÊCHEUX, 1969, p. 76-77).

Quando o sujeito enuncia, mobiliza um funcionamento discursivo, que remete às formações imaginárias. Estas são representações que o sujeito faz de si, do outro, do outro em relação a si, do objeto do discurso. O sujeito tem a ilusão deque o sentido chega ao interlocutor da forma como espera e isso faz parte da formação imaginária do sujeito falante. $\mathrm{O}$ que o sujeito espera que faça sentido para o interlocutor se conjuga sempre sobre um discurso prévio.

A partir do que foi exposto, pode-se concluir que não são os lugares empíricos, ocupados pelo sujeito que determinam seus dizeres, mas as representações das posições ocupadas por cada sujeito e também do referente. 
Outra noção pertinente a este trabalho é a memória discursiva. Para Pêcheux (1999, 1975, 1988) o discurso, enquanto acontecimento, é o encontro entre uma atualidade e uma memória. Para Orlandi, a memória é o mesmo que interdiscurso, ou seja, formulações feitas e esquecidas, que fazem sentido em nosso discurso, porque já faziam sentido antes e esta é a concepção adotada neste artigo. Pêcheux $(1999,1969)$ Pêcheux e Fuchs (1975) também compreende memória discursiva como interdiscurso. A memória é o saber discursivo, falado anteriormente, em outro lugar, independentemente. A memória é o já-dito constituído ao longo da história e que atravessa nossos discursos.

Outra noção basilar neste artigo é a concepção de efeitos metafóricos. De acordo com Pêcheux (1969, p.96):

chamaremos efeito metafórico o fenômeno semântico produzido por uma substituição contextual, para lembrar que esse "deslizamento de sentido" entre x e y é constitutivo do "sentido" designado por x e y; esse efeito é característico dos sistemas linguísticos "naturais" por oposição aos códigos e às "línguas artificiais" [...]. (PÊCHEUX, 1969, p. 96).

O efeito metafórico é um efeito semântico que pode ser substituído contextualmente por outro, sem que dele se desligue totalmente. É instaurado pela posição sujeito social, histórico, cultural e sua relação com a Formação Discursiva (FD), com a ideologia, a memória discursiva. Conforme Orlandi, retomar não é o mesmo que repetir, pois o sentido pode ser sempre outro, já que o efeito metafórico, a deriva, o deslizamento estão funcionando com a memória. Segundo Orlandi (2013), a metáfora é constitutiva da produção do sujeito e do sentido. Não é percebida como desvio, mas como transferência. $\mathrm{O}$ trabalho produzido pelo efeito metafórico, pelo deslize, mostra a produção de sentidos constituídos por um "outro" possível.

Pêcheux $(2008,2009)$ afirma que todo enunciado possui pontos de deriva possíveis, é suscetível de tornar-se outro, é o efeito metafórico deslocando seu sentido para outros diferentes de si mesmo. Para o autor, não há sentido sem metáfora.

[...] o sentido é sempre uma palavra, uma expressão ou uma proposição por uma outra palavra, uma outra expressão ou proposição; e esse relacionamento, essa superposição, essa transferência (metaphora), pela qual elementos significantes passam a se confrontar, de modo que "se revestem de um sentido" não poderia ser predeterminada por propriedades da língua: [...] de fato, o sentido, existe exclusivamente nas relações de metáfora (realizadas em efeitos de substituição, paráfrases, formações de sinônimos), das quais certa formação discursiva vem a ser historicamente o lugar mais ou menos provisório: as palavras, expressões e proposições recebem seus sentidos da formação discursiva à qual pertencem [...] (PÊCHEUX, 2009, p. 239-240).

Desta forma, o efeito metafórico, percebido como uma substituição contextual, promove um deslizamento de sentido entre termos linguísticos, dependendo do processo discursivo e das condições de produção desse discurso. De acordo com Pêcheux (2009, p. 148), “[...] as mesmas palavras, expressões, proposições mudam de sentido ao passar 
de uma formação discursiva a uma outra" [...]. Ademais, segundo o autor, "[...] as palavras, expressões, proposições etc., mudam de sentido segundo as posições sustentadas por aqueles que as empregam" [...] (PÊCHEUX, 2009, p.146-147). A depender da posição ideológica ocupada pelo sujeito, a mesma palavra pode significar diferentemente. De acordo com Orlandi (2012a), efeito metafórico é deriva, deslocamento, transferência.

Parafraseando Possenti (1995), o preconceito à homossexualidade estando vivo na sociedade, a existência para tal leitura aumenta.

\section{ASPECTO METODOLÓGICO}

O universo da pesquisa foi constituído por reportagem retirada do Jornal Nacional, disponível em: https://globoplay.globo.com/v/6980200/, acessado em vídeo em: 01 de /11/2020e de sites de jornais que abordaram o mesmo assunto, no mesmo dia.

Os comentários dos internautas foram extraídos do jornal Folha de Pernambuco. (Disponível em:https://www.folhape.com.br/politica/virei-boiola-igual-maranhense-dizbolsonaro-no-maranhao-apos-beber/160111/. Acesso em: 01 de nov. de 2020). A matéria jornalística será analisada, a seguir, à luz do dispositivo teórico e analítico da Análise do Discurso de linha francesa.

\section{TRABALHO ANALÍTICO NUM CORPUS DISCURSIVO}

O internauta que se marca na publicação como André Lopes comenta:

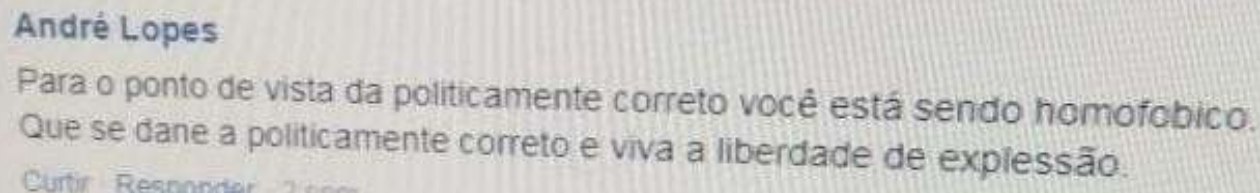

Pode-se perceber no primeiro comentário como a memória discursiva é acionada, pois, de acordo com a posição-sujeito que Bolsonaro ocupa, não poderia referir-se a integrantes da comunidade LGBT (lésbicas, gays, bissexuais e transexuais) como "boiola". Como afirma Pêcheux (1969); Pêcheux e Fuchs (1975); Pêcheux (2009), algo fala antes, em outro lugar, independentemente e diferentemente. Quando o internauta diz dane-se o politicamente correto, tal enunciado se inscreve numa memória atual, que acessa uma rede de memórias sobre a campanha política para disputa à presidência de Bolsonaro e referência do internauta à Constituição, que contém, dentre seus princípios, respeito à liberdade de expressão. Sabe-se, desde sua campanha política, que o presidente não concorda com relações homoafetivas e sempre marcou sua posição de preservar o formato de família heteronormativa. Segundo Possenti (1995), a palavra produz efeitos de sentido em decorrência de quem profere tal discurso.

O enunciado dane-se o politicamente correto produz o efeito metafórico de que não importa o que é dito, se produz sentido pejorativo, ou não, a integrantes da comunidade LGBT; a liberdade de expressão garantida pela Constituição permite ao sujeito falar o que quiser, quando quiser, independente da posição-sujeito no enunciado, 
sem limites ou de acordo com o politicamente correto. Conforme Pêcheux (2009), a FD em que se inscreve o sujeito regula o que pode e deve ser dito. A posição-sujeito de Presidente do Brasil permite a circulação de certos dizeres e a interdição de outros. Segundo Orlandi (2012b, 2012c, 2013) a AD não trabalha com a literalidade, mas com a opacidade do texto, como ele funciona, produz sentidos. Assim, nem tudo se pode dizer em uma determinada formação discursiva/ideológica.

O enunciado do internauta aponta que o silêncio é o amálgama de posições heterogêneas como afirma Orlandi (2007). Ora o internauta produz o efeito de se marcar em uma posição, ora em outra. Por último deixa silenciado, que nenhum modo de dizer pode ser interditado. Conforme Indursky (2011), o fechamento das FDs não é rígido, suas fronteiras são porosas, pois existe uma movência de saberes e sentidos. Dentro de uma formação discursiva existe entre os saberes uma relação de aliança, conforto, refutação, ou seja, a contradição é constitutiva. Em suas formações imaginárias, o internauta sustenta um discurso que não importa o que se diga, pois cada um é livre para dizer o que está com vontade. $\mathrm{O}$ enunciado do internauta produz o sentido que o identifica à formação discursiva de apoiador de Bolsonaro. $\mathrm{O}$ enunciado inscrito na historicidade por meio da exterioridade constitutiva acessa uma rede de memórias que retomam os ataques ao Supremo Tribunal Federal, as fakenews supostamente produzidas pelos apoiadores de Bolsonaro e o presidente justificando tais manifestações como "liberdade de expressão". comenta:

O segundo internauta, que se marca na publicação como Danielle Chacon,

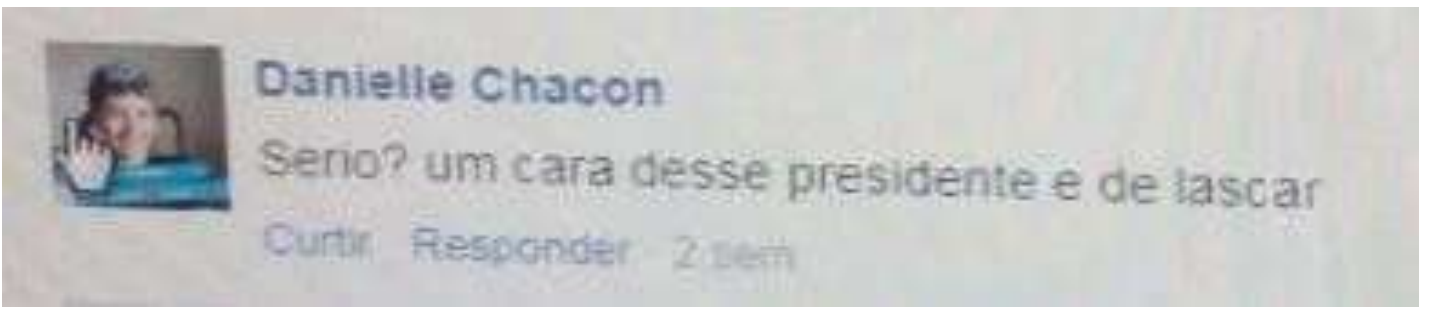

O termo interrogativo sério silencia sentidos entre eles o de não acreditar que nas condições de produção de chefe do poder executivo Bolsonaro tenha postado em redes sociais a "piada" envolvendo a cor de uma bebida típica do Maranhão com a orientação de gênero de quem a bebe.

O termo sentidos o linguístico lascar marca, na superfície linguística, a indignação, o absurdo, a perplexidade. Produz efeitos metafóricos que, ocupando a posição-sujeito presidente, Bolsonaro não deveria demostrar preconceito, proferir discursos de cunho homofóbico, já que se sabe que não se pode controlar o sentido que chega ao interlocutor, ao ouvinte. A linguagem é incompleta, sujeita a falhas, furos, equívocos, como afirma Pêcheux (1969), Pêcheux e Fuchs (1975), 1999, 2008, 2009); Orlandi (2012a, 2012b, 2012c, 2011, 2013, 2017); Indurky (2011a, 2011b). Parafraseando Bacahuí (2010), acredita-se que os enunciados midiáticos se inscrevem em redes de memória e que permanecem num diálogo interdiscursivo, através de imagens, representações, utilizadas ora para fixar, ora para desconstruir identidades. Desde antes da candidatura à presidência do Brasil, Bolsonaro sempre valorizou o formato de família heteronormativo e nunca se manifestou a favor da 
homossexualidade, o que o marcou como identificado ao preconceito, à homofobia. Desse modo, concordando com Pêcheux (2009, p. 239) “o sentido é sempre uma palavra, uma expressão ou uma proposição por uma outra palavra, uma outra expressão ou proposição" [...]. O sujeito internauta atribui imagens ao outro, Bolsonaro, que remete às formações imaginárias. Isso faz retomar os mecanismos de seu funcionamento. As relações de sentido de força e antecipação. Um discurso aponta para outros; os dizeres têm mais valor, dependendo da posição-sujeito ocupada; a antecipação é se colocar no lugar do ouvinte a partir do próprio lugar. A internauta produz o efeito de sentido que questiona: como alguém que representa o chefe do executivo de um país é capaz de enunciar certos dizeres publicamente?

O enunciado da internauta marca uma memória social sobre posicionamentos do presidente no passado e que per(insiste) no momento atual e que se fundam em distintas conjunturas sócio históricas reverberando o "mesmo".

\section{ENUNCIADO DO PRESIDENTE JAIR BOLSONARO NOS JORNAIS}

"Agora virei boiola igual maranhense, é isso? Olha, o guaraná cor-de-rosa do Maranhão aí ó! Quem toma esse guaraná aqui vira maranhense, hein? Guaraná cor-derosa do Maranhão...que boiolagem isso aqui”.

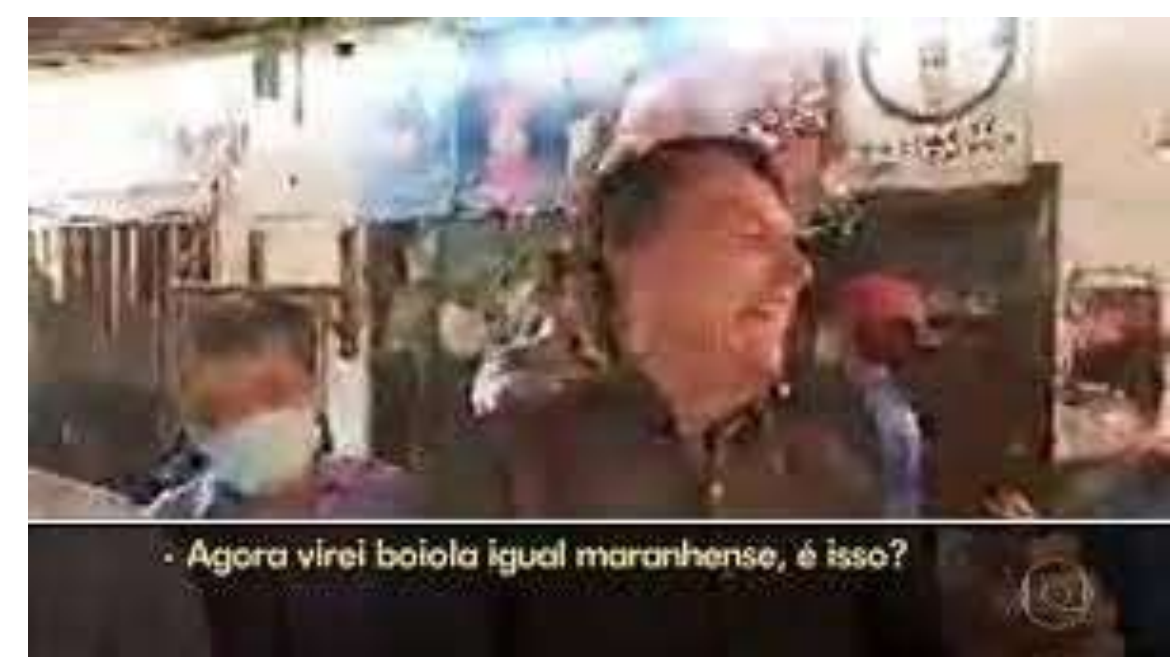

"O silêncio trabalha politicamente, significando o que não pode ser dito" (ORLANDI, 2012, p.20). Enquanto Bolsonaro enunciava tais dizeres, silenciava outros, ao mesmo tempo que sentidos indesejáveis circularam. No discurso do presidente, percebe-se a memória discursiva retomando seus dizeres quando era candidato. Em 28/08/2018 (Disponível em: https://globoplay.globo.com/v/6980200/. Acesso em: 04 nov. de 2020), em entrevista ao Jornal Nacional, o então candidato Jair Messias Bolsonaro "confirma certos discursos" em entrevista com William Bonner e Renata Vasconcellos. A repórter o questionou: "Se o senhor afirma não ser homofóbico, como já disse que um vizinho gay desvaloriza imóvel? Que prefere ver um filho morto a ser gay? O senhor já associou pedofilia a homossexualismo. ${ }^{3} \mathrm{O}$ então candidato justificou que se referiu a algo ocorrido nos corredores da Câmara. Tratava-se de uma

\footnotetext{
${ }^{3}$ Termo de teor pejorativo enfatizado por William Bonner na entrevista, o termo seria homossexualidade.
} 
comemoração do nono seminário LGBT infantil, que apresentava um material distribuído nas escolas públicas, o kit gay. Bolsonaro afirmou se referir ao plano Nacional de promoção e cidadania LGBT que, entre seus 180 itens, defende a desconstrução da heteronormatividade; seu discurso foi em defesa das crianças em sala de aula.

Em 29/10/2018, o site da Cartacapital.com.br traz a manchete: Bolsonaro em 25 frases polêmicas. Entre as frases proferidas estão: (2010), "o filho começa a ficar assim meio gayzinho, leva um couro, ele muda". (2012), "90\% desses meninos adotados [por um casal gay] vão ser homossexuais e vão ser garotos de programa com toda certeza" Em 14/08/2015 no site: https://www20.opovo.com.br, em matéria intitulada: confira dez frases polêmicas de Jair Bolsonaro, na época deputado, Bolsonaro afirmou" seria incapaz de amar um filho homossexual" [...]

Em 14/04/2015 no site veja.abril.com.br, com o título: Bolsonaro é condenado a pagar RS 150 mil reais por comentário contra gays, o então deputado comenta sobre o kit gay 2:" não estou perseguindo boiola. Deixar bem claro, o assunto é sério. Esse pessoal não se cansa. Lançaram o kit gay 2" [...]. Bolsonaro afirma que não participaria de um desfile gay porque não promoveria "maus costumes", assim como acredita em Deus e na preservação da família. O discurso de Bolsonaro, em sua carreira política, sempre produziu efeitos de sentido de antagonismo à comunidade LGBT.

Neste artigo serão analisados a reportagem do Jornal Nacional exibida em 29/10/2020, acerca do discurso do presidente sobre a cor rosa do refrigerante Jesus no Maranhão, e dois comentários de internautas no site da Folha de Pernambuco, no mesmo dia.

A cor rosa produz o efeito do feminino e metonimicamente (parte pelo todo) passou a identificar os gays em geral. Interpelado pela ideologia de sujeito evangélico, no funcionamento do seu silêncio, os sentidos desdobram-se. O que é apagado no discurso do presidente clama por múltiplos sentidos. Significando pelo que (não) pode e (não) deve ser dito. Os termos boiola, rosa, apontam para a exterioridade constitutiva de sujeito "marica", "efeminado", "homossexual". Ao referir-se à cor rosa do refrigerante, Bolsonaro reproduz dizeres do senso comum como: "isso é coisa de gay". Isto retoma a memória social em relação a padrões heteronormativos. Segundo Davallon (1999, p. 25) para que haja memória social, é preciso que o acontecimento ganhe significância. "[...] há necessidade que o acontecimento lembrado reencontre sua vivacidade; e, sobretudo, é preciso que ele seja reconstruído a partir de dados e de noções comuns aos diferentes membros da comunidade social." O funcionamento da memória social ocorre através de objetos culturais como filmes, imagens, mídia, dentre outros.

Conforme Filgueiras $(2019$, p.62) "[...] são, por exemplo, imagens e filmes que produzem efeitos de sentido e legitimam como deve se portar socialmente, falar e se vestir uma mulher/homem para que assuma posições sujeito daquele gênero. É o momento em que a memória social opera e legitima acessórios, roupas e utensílios voltados para o gênero masculino e feminino, cores e brinquedos tipicamente desenvolvidos para „meninas ou para "meninos”, o que é um efeito da atuação da ideologia da classe dominante". Foi culturalmente construído que a cor rosa destina-se a mulheres/gays e isso reverbera no discurso do presidente. "[...] Memória é tudo que 
pode deixar marcas de tempos disjuntados que nós vivemos e que nos permite a todo o momento fazer surgir e reunir as temporalidades passadas, presentes e que estão por vir [...]" (SCHERER, TASCHETTO, 2005). A memória discursiva aqui tratada como interdiscurso não se refere à memória individual, cognitiva, mas a ecos de saberes que alinhavam nossos discursos advindos de distintas temporalidades e que nos inscreve em uma dada formação discursiva. Conforme Camargo:

\begin{abstract}
a formação discursiva, como a memória discursiva, constrói-se com base na sua historicidade e esta relaciona-se com a interdiscursividade formada por memórias sociais constituintes de uma formação discursiva. Essas memórias sociais são constituintes da memória discursiva e são fruto dos aparelhos ideológicos de Estado juntamente com o intradiscurso, são formadas pela atualidade do discurso e pelas suas relações com o presente. A Memória Discursiva se estabelece pela relação entre intradiscurso e interdiscurso, logo, essa dualidade relacional objetiva evocar um sentido de origem, na qual a repetição dos discursos fortalece sua presença, porém, outra possibilidade encontra-se na memória fragmentada, que busca a construção do discurso pelo apagamento. (CAMARGO, 2019, p.178)
\end{abstract}

O discurso do presidente retoma a memória social constitutiva da memória discursiva e faz ressoar sentidos de discriminação. Ao "brincar" com a cor do refrigerante maranhense, Bolsonaro dá visibilidade ao movimento de ontem (quando era deputado) e ao de hoje (presidente). Em 2018, candidato à presidência e, atualmente, Presidente da República, certos sentidos são autorizados a circular na formação discursiva de Bolsonaro e outros sentidos desautorizados, ressoando efeitos de sentido negativo, pois deslocam para sentidos de críticas, preconceitos. Termos como boiola, boiolagem se inscrevem na historicidade para produzir novos efeitos de sentido que sugerem humor e preconceito, ao insinuar que o sujeito que toma o refrigerante rosa do Maranhão, vira "boiola" termo este cognominado aos gays. Conforme Orlandi (2013), o dito carrega consigo o pressuposto (não-dito) e ao longo do dizer há não ditos que também significam. Os dizeres de Bolsonaro apontam para uma ausência presente, que faz acionar a memória atual e uma rede de memórias sobre posicionamentos contraditórios desde quando era deputado, atravessando sua campanha política até o momento vigente. Conforme Orlandi (2013, p.33), "a constituição determina a formulação, pois só podemos dizer (formular) se nos colocarmos na perspectiva do dizível (interdiscurso, memória) [...]”. Deste modo, a memória e o interdiscurso são responsáveis pela constituição do sentido. Conforme Pêcheux (1969); Pêcheux e Fuchs (1975); Pêcheux (1999, 2009), o interdiscurso ou memória discursiva corresponde a algo que fala antes, em outro lugar, independentemente. O interdiscurso se relaciona ao complexo com dominante de formações discursivas. É o já-dito que alicerça o dizível, sustentando cada tomada da palavra, conforme salienta Orlandi (1998, 2012a, 2012b, 2012c, 2011, 2013, 2017).

O interdiscurso determina a formação discursiva e esta é responsável pela constituição de sentidos e identificação dos sujeitos, de acordo com Pêcheux e Fuchs (1975) e Pêcheux (2009). O discurso de Bolsonaro produz efeitos de sentidos que o marcam como alguém que se identifica com o conservadorismo, com a "família tradicional cristã heteronormativa", propagador de "bons costumes". São saberes e 
sentidos que circulam, desse modo, a partir de sua inscrição em uma formação discursiva de extrema direita conservadora.

\section{CONSIDERAÇÕES FINAIS}

Segundo Orlandi (1998, 2012a, 2012b, 2012c, 2011, 2013, 2017), sentidos e sujeitos constituem-se mutuamente. Os sujeitos internautas interpelados por diferentes ideologias assumem uma posição, afetados por dizeres anteriores (interdiscurso, memória).

$\mathrm{Na} \mathrm{AD}$, a exterioridade (interdiscurso) determina a interioridade (intradiscurso). Percebe-se na atividade tensional entre paráfrase e polissemia o efeito de incompletude, falta, furo no sistema simbólico, abrindo espaço para o possível, lugar de funcionamento do efeito metafórico. Nesse direcionamento, o discurso do Presidente se mostrou atravessado pelo "esquecimento n" 2", de Pêcheux, no qual o sujeito tem a ilusão de que o que diz tenha apenas um significado. O sujeito não pode controlar os efeitos de sentido que o seu discurso produz no ouvinte.

Ao enunciar ironicamente sobre a cor do refrigerante do Maranhão, por acreditar que seus interlocutores achariam engraçado, não produziu o efeito esperado, pois houve resistência nas redes sociais e seu enunciado deslizou metaforicamente para a homofobia, associando cor à gênero. Acionando a memória social, discursiva, o discurso do Presidente e dos internautas retoma e reatualiza o já-dito, produzindo novos efeitos de sentido. A memória discursiva se mostrou funcionando conforme defende Pêcheux $(1999,2009)$, pois todo discurso produz sentidos a partir de outros sentidos, já sedimentados socialmente.

Foi possível também perceber o já-dito, ou seja, a memória discursiva ou interdiscurso, que retomaram enunciados polêmicos do Presidente acerca da comunidade LGBT na época em que era Deputado Federal. O discurso do internauta produziu um efeito de silenciamento (censura) ao posicionamento de não considerar a cor relacionada a gênero e à homossexualidade.

Este trabalho mobilizou um gesto de leitura e interpretação, ancorado na $\mathrm{AD}$, acerca do discurso do atual presidente Jair Messias Bolsonaro em reportagem do Jornal Nacional em outubro de 2020, bem como a repercussão nacional produzida e comentários de dois internautas em reação ao discurso do presidente. Conforme Pêcheux (1999, 2009) somos constituídos pelo outro (interlocutor), pelo Outro (interdiscurso) que atravessam nossos discursos e se inscrevem numa memória discursiva, e essa não pode ser concebida ao modo de um reservatório, como um frasco sem exterior.

Este artigo analisou projeções sociais sobre "o que (não) pode e (não) deve ser dito" na posição-sujeito presidente de um país, inscrito nessa FD, conforme se observou nos comentários dos internautas. Dessa forma, analisou-se que não são os lugares empíricos, ocupados pelos sujeitos, que determinam seus dizeres, mas a representação que o sujeito faz do outro, de si, do outro em relação a si e também do referente, que orienta a produção do discurso e o processo de constituição dos sentidos. Nas formações imaginárias aqui analisadas, há sentidos cristalizados que apontam para a posição- 
sujeito presidente como lugar social que segue liturgias, decoro, que pode impactar o ouvinte, caso sejam desrespeitados. Assim, há determinações sócio históricas que apontam "para o que pode e deve ser dito", partindo da posição-sujeito de presidente do Brasil.

\section{REFERÊNCIAS}

Bolsonaro é condenado a pagar \$ 150 mil por comentário contra gays. Disponível em: https://veja.abril.com.br/politica/bolsonaro-e-condenado-a-pagar-r-150-mil-porcomentario-contra-gays/. Acesso em: 27 jan de 2021.

Bolsonaro em 25 frases polêmicas. Disponível em: https://www.cartacapital.com.br/ politica/bolsonaro-em-25-frases-polemicas/. Acesso em; 27 jan de 2021.

CAMARGO, Cassio M. dos. Memória discursiva e análise do discurso na perspectiva pecheutiana e sua relação com a memória social. Revista saber humano, v.9, n. 14, p.167-181, jan/jun, 2019.

Confira dez declarações polêmicas de Jair Bolsonaro. Disponível em: https://www20. opovo.com.br/app/politica/2015/08/14/noticiaspoliticas,3486769/confira-dez-

declaracoes-polemicas-de-jair-bolsonaro.shtml. Acesso em: 27 jan de 2021.

DAVALLON, Jean. A imagem uma arte de memória? In: ACHARD, Pierre et al. (orgs.) Papel da memória. Nunes Campinas: Pontes, 1999, p.23-32.

DIÁRIO DE PERNAMBUCO. 'Virei boiola igual maranhense', diz Bolsonaro após beber refrigerante rosa típico do Maranhão. Disponível em: https://www.diariode pernambuco.com.br/noticia/politica/2020/10/virei-boiola-igual-maranhense-diz-

bolsonaro-apos-beber-refrigerant.html. Acesso em: 03 nov de 2020.

FILGUEIRAS, Arthur de A. Formações discursivas atravessadas e identidades em trânsito: uma análise discursiva da/sobre transexuais. Tese (doutorado). Universidade Católica de Pernambuco - UNICAP. Programa de pós-graduação em Ciências da Linguagem. Doutorado em Ciências da Linguagem. 2019.

GLOBOPLAY. Ameaçado de processo por Dino, Bolsonaro pediu desculpas por brincadeira no Maranhão. Disponível em: https://globoplay.globo.com/v/8981819/. Acesso e: 03 nov de 2020.

INDURSKY, Freda. A memória na cena do discurso. In: INDURSKY, Freda; MITTMANN, Solange; FERREIRA, Maria C. L. Memória e História na/da Análise do Discurso. Campinas, SP: Mercado de Letras, 2011, p. 67-88.

JORNAL DE BRASÍLIA. Bolsonaro faz piada com refrigerante cor-de-rosa do Maranhão e recebe críticas. Disponível em: https://jornaldebrasilia.com.br/politica-epoder/bolsonaro-pede-desculpas-por-fala-preconceituosa-apos-tomar-guarana-nomaranhao/. Acesso em: 03 nov de 2020.

JORNAL DE BRASÍLIA. Bolsonaro faz piada preconceituosa no Maranhão: "virei boiola, igual maranhense". Disponível em: https://jornaldebrasilia.com.br/politica-epoder/bolsonaro-faz-piada-preconceituosa-no-ma-virei-boiola-igual-maranhense/.

Acesso em: 03 nov de 2020.

JOVEMPAN. Bolsonaro pede desculpas por fala preconceituosa após tomar guaraná no Maranhão. Disponível em: https://jovempan.com.br/programas/jornal-damanha/ ameacado-de-processo-por-dino-bolsonaro-pede-desculpas-por-brincadeira-nomaranhao.html. Acesso em: 03 nov de 2020.

ORLANDI, Eni P. Análise de Discurso: princípios e procedimentos. Campinas: Pontes, 2013. 
ORLANDI, Eni P. Discurso e argumentação: um observatório do político. Fórum Linguístico, v. 1, n.1, p. 73-81, 1998. Disponível em: file:///C:/Users/user/Downloads/ 6915-Texto\%20do\%20Artigo-20890-1-10-20080923.PDF. Acesso em: 03 nov. de 2020.

ORLANDI, Eni, P. Discurso e leitura. 9. ed. São Paulo: Cortez, 2012b.

ORLANDI, Eni, P. Discurso e texto. Formulação e circulação dos sentidos. 4. ed. São Paulo: Pontes, 2012c.

ORLANDI, Eni, P. Discurso em análise. Sujeito, sentido, ideologia. 2. ed. Campinas: Pontes Editores, 2012a.

ORLANDI, Eni.P. Eu, Tu, Ele: Discurso e real da história. 2. ed. Campinas, SP: Pontes Editores, 2017.

PÊCHEUX, Michel. Análise automática do discurso (AAD-69). In: GADET, Françoise; HAK, Tony (orgs). Por uma análise automática do discurso. Uma introdução à obra de Michel Pêcheux. 5. ed. Campinas, SP: Editora da Unicamp, 2014, p. 59-96.

PÊCHEUX, Michel. Discurso: estrutura ou acontecimento. 5. ed. Campinas: Pontes, 2008.

PÊCHEUX, Michel. Papel da memória. In: ACHARD, Pierre et al. (orgs.) Papel da memória. Nunes Campinas: Pontes, 1999, 49-67.

PÊCHEUX, Michel. Semântica e discurso. 4. ed. Campinas: Editora da UNICAMP, 2009, p.137-281.

PÊCHEUX, Michel; FUCHS, Catherine. A propósito da análise automática do discurso: atualização e perspectivas (1975). In: GADET, Françoise; HAK, Tony (orgs). Por uma análise automática do discurso. Uma introdução à obra de Michel Pêcheux. 5. ed. Campinas, SP:Editora da Unicamp, 2014, p.159-231.

POSSENTI, Sírio. A linguagem politicamente correta e a Análise do Discurso. Disponível em: http://www.periodicos.letras.ufmg.br/index.php/relin/article/view/1016. Acesso em: 1 nov de 2020.

REVISTA FÓRUM. Guaraná Jesus, apesar do nome, foi criado por um ateu; conheça a história. Disponível em: https://revistaforum.com.br/cultura/guarana-jesusapesar-do-nome-foi-criado-por-um-ateu-conheca-a-historia/. Acesso em: 05 nov de 2020.

SILVA, Dalexon S. da. O que é Golden shower? Efeitos de sentido sobre o lugar de presidente Bolsonaro no twitter. Revista Dissol, Pouso Alegre, ano 5, n.9, 2019. Disponível em: http://ojs.univas.edu.br/index.php/revistadissol/login?source $=\% 2$ Findex.php\%2Frevistadissol\%2Farticle\%2Fdownload\%2F563\%2F333. Acesso em: 30 out de 2020.

Artigo recebido em: nov. de 2020.

Aprovado e revisado em: jan. de 2021.

Publicado em: fev. de 2021.

Para citar este texto:

CAVALCANTI, Maria do Carmo Gomes Pereira; AZEVEDO, Nadia Pereira Gonçalves de. Cor versus gênero: Análise discursiva do discurso de Bolsonaro no Maranhão e comentários de internautas. Entremeios [Revista de Estudos do Discurso, ISSN 2179-3514, on-line, www.entremeios.inf.br], Seção Estudos, Programa de Pós-Graduação em Ciências da Linguagem (PPGCL), Universidade do Vale do Sapucaí (UNIVÁS), Pouso Alegre (MG), vol. 23, p. 129-142, Edição especial/ 2020. DOI: http://dx.doi.org/10.20337/ISSN21793514revistaENTREMEIOSvol23pagina129a142 